\title{
La Cultura en la Cumbre (en torno al Plan Estratégico de Gobierno, una crítica y una propuesta, en el terreno de la acción cultural).
}

\author{
Carlos Fong ${ }^{1, *}$ \\ ${ }^{1}$ Escritor, activista y promotor cultural. \\ *Autor para correspondencia. Email: carlosfong27@gmail.com
}

\begin{abstract}
"Es ya tiempo de que los gobernantes entiendan que la ciencia y, en general, la cultura no son solamente un instrumento de desarrollo económico, sino también y en primer lugar un bien intrínsecamente valioso"

Mario Bunge
\end{abstract}

\section{Un referente histórico imprescindible:}

En el año 1982 la UNESCO convocó a la Conferencia Mundial sobre Políticas Culturales. Como consecuencia, las Naciones Unidas declaró el período de 1988 a 1997 como el Decenio Mundial para el Desarrollo Cultural. La Declaración que salió de aquella Conferencia apelaba a nuevas líneas orientadas a revalorar la noción del desarrollo de los individuos y la sociedad. Solicitaba a las políticas culturales "a que protejan, estimulen y enriquezcan la identidad y el patrimonio cultural de cada pueblo; además, que establezcan el más absoluto respeto y aprecio por las minorías culturales, y por las otras culturas del mundo. La humanidad se empobrece cuando se ignora o destruye la cultura de un grupo determinado".

Por este motivo, se dieron muchas acciones concretas como seminarios y congresos internacionales destinados al estudio y a la investigación de la noción de desarrollo cultural. Empezaban a tener forma nociones como Cultura y Desarrollo que hasta el momento habían estado concebidas de forma separada.

Entre el caudal de iniciativas podemos recordar el seminario-taller internacional: "Las dimensiones culturales del desarrollo y la integración: políticas y proyectos", convocado por el Instituto Andino de Artes Populares (IADAD) celebrado en Quito en 1997; o el "Segundo encuentro iberoamericano sobre cultura y desarrollo, retos y estrategias", convocado por el Centro de superación para la cultura, del gobierno cubano; y, en 1998 en Estocolmo, la "Conferencia intergubernamental sobre políticas 
culturales para del desarrollo" dedicada por la UNESCO y las Naciones Unidas para cerrar dicho período.

Sin embargo, al final del decenio de los 90, siguieron algunas acciones como el "Primer congreso internacional de cultura y desarrollo: el desarrollo cultural" desde una perspectiva ética celebrado en Cuba en 1999; y a comienzos de agosto, del mismo año, se dio el encuentro: "Cultura y Desarrollo: la perspectiva regional/local” organizado por el IADAP. Y no olvidemos La Declaración de Margarita, que nació del Primer Encuentro Iberoamericano de Ministros de Cultura, celebrado en Venezuela en 1997, donde los ministros de cultura se comprometían a "impulsar políticas culturales, cuyo propósito se fundamente en el concepto que sitúa al hombre como sujeto y objeto de la cultura, en las que éstas se constituyan en el eje del desarrollo humano".

La idea de impulsar políticas culturales, cuyo propósito se fundamente en el concepto que sitúa al hombre como sujeto y objeto de la cultura, en las que éstas se constituyan en el eje del desarrollo humano, cobró fuerza desde entonces y ha corrido mucha tinta sobre el tema. El siglo XXI se abría con una nueva mirada hacia los procesos culturales. Una gran diversidad de investigaciones, publicaciones, estudios de científicos sociales de la talla de Néstor García Canclini, Jesús Martín-Barbero, Ernesto Ottone, Oscar Landi, María Immacolata Vassallo de Lopéz, Ernesto Piedras, Marcelino Bisbal, Germán Rey Beltrán, entre muchos otros, acuñaron una serie de términos y conceptos que ayudaron a edificar un discurso y, en el mejor de los casos, un método de trabajo para que la cultura trascienda la concepción de desarrollo desde lo meramente económico-industrial.

\section{Hacia una nueva mirada de la cultura.}

La noción de desarrollo cultural se formuló, explícitamente, por primera vez, en ocasión de la "Conferencia internacional sobre los aspectos institucionales, administrativos y financieros de las políticas culturales", organizada por la UNESCO en Venecia en 1970. El propósito de la conferencia era ampliar y corregir una concepción demasiado economista del desarrollo (Desarrollo Cultural y Desarrollo Global de Claude Fabricio, 1982).

Aquella concepción estaba asociada de manera orgánica a la historia del crecimiento de las sociedades industriales en Europa, desde finales de siglo XVIII, al progreso económico norteamericano durante la segunda mitad del siglo XIX, y desde fines de la Primera Guerra Mundial. En los años sesenta se pone en duda el desarrollo concebido solo en términos económicos y nacen nuevas concepciones como ecodesarrollo, desarrollo endógeno y también desarrollo autocentrado en las relaciones sociales, la cultura y las instituciones políticas de la colectividad. Empieza la preocupación de si los estadosnación pueden orientar su desarrollo regional y local desde un punto de vista cultural-histórico.

Hace 17 años, el filósofo Mario Bunge había aconsejado que un modelo de desarrollo exclusivamente económico y político era un error costosísimo. Las palabras del pensador argentino aún siguen haciendo eco. Bunge sostenía que una nación es un sistema compuesto de tres subsistemas entrelazados entre sí: económico, cultural y político. Apostaba por un modelo de desarrollo integral que combinaba 
Invest. pens. crit.

Vol. 3, No. 3, septiembre-diciembre 2015

pp. $80-90$

un modelo biológico, económico, cultural, político e integral. "Solamente los malos economistas creen que los problemas económicos pueden desligarse de los demás y resolverse con medidas puramente económicas...", afirma Bunge.

Una concepción integral de desarrollo combina todos los modelos porque la sociedad es un sistema donde la salud de uno depende de la salud de los demás. En consecuencia, el progreso auténtico y sostenido es integral. Escribe Bunge:

La sociedad humana no es ni un bloque macizo ni un mero conjunto de individuos, sino un sistema concreto analizable en cuatro subsistemas principales. Éstos son el sistema biológico (mantenido por los lazos de familia), el sistema económico (mantenido por las relaciones de producción), el sistema cultural (mantenido por las relaciones de información) y el sistema político (mantenido por las relaciones de poder). Cada uno de estos subsistemas interactúa fuertemente con los otros tres, por lo cual ninguno de ellos se desarrolla de manera autónoma, es decir, independientemente de los demás. Más aún, cada uno de los cuatro subsistemas tiene componentes biológicos, económicos, culturales y políticos.

La cultura es un componente clave para el desarrollo de un país. Sin cultura -esto es la ciencia, la técnica, las ciencias sociales (las humanidades) y las artes-, cualquier modelo de desarrollo está condenado al fracaso. Un plan de desarrollo, para contener una estrategia sostenible, debe ser integral, aunque la elección de ese modelo sea una decisión política de determinada ideología. El problema es cuando la ideología se inclina sólo por la economía. "Al fin y al cabo la economía no es un fin sino un medio para vivir una vida plena", dice Bunge.

Hoy sabemos (incluso lo han admitido organismos internacionales como el BID) que para que exista un cambio que resuelva los males que afectan al mundo, los mismos tienen que ser de carácter cultural. Empezamos a escuchar que la cultura no es algo ajeno a una política de desarrollo social. La cultura es objeto mismo de desarrollo; tratar el desarrollo desde una concepción cultural no excluye las concepciones de carácter técnico-económico; la visión de desarrollo cultural no se reduce ni se limita al espacio donde se encuentran los sectores vinculados estrechamente a la cultura (industrias culturales, artesanías, patrimonio cultural, turismo cultural, etc.).

La mirada profunda del desarrollo cultural está implícita en todas las políticas: de economía, de educación, de salud, de deporte, de ambiente, de prevención y de la política-política. La cultura, quieran o no los políticos, quienes en última instancia son los que toman las decisiones políticas, está inserta de manera innata en todo. La dualidad entre economía y cultura no existe. Las nociones de desarrollo clásico han evolucionado. Para que exista un verdadero desarrollo integral es necesario ver la realidad desde un punto más amplio que incluya un pensamiento económico, social, antropológico, filosófico, pedagógico y, desde luego, cultural, para que de esta forma podamos salir de los fundamentalismos estrechos que nos tienen viviendo en el siglo pasado en términos educativos y culturales. 
Diversos documentos, informes y memorias, acumulados en las sucesivas Cumbres Mundiales sobre el Desarrollo Sostenible, comenzando por aquella en Estocolmo en 1972, pasando por la de Rio de Janeiro en 1992, hasta la de Johannesburgo en 2002, sin olvidar Informe Mundial de Cultura y Desarrollo: Nuestra diversidad creativa que la UNESCO publicó en 1995, donde explícitamente se cuestionaba: “¿Cómo pueden los países definir políticas culturales encaminadas a fomentar un pluralismo realmente constructivo en el que la diversidad sea una fuente de creatividad? ¿Cómo convencer a los responsables de tomar decisiones de que apoyar las formas y expresiones artísticas nuevas, emergentes y experimentales no significa subvencionar el consumo, sino invertir en el desarrollo humano?”

Todos estos documentos y declaraciones firmados por Ministros y Mandatarios, como los famosos Objetivos de Desarrollo del Milenio (ODM) que fueron acogidos por los Estados miembro de ONU en el año 2000, en la Cumbre del Milenio; o la Carta Cultural Iberoamericana, documento aprobado en Uruguay en el año 2006, en el marco de la XVI Cumbre Iberoamericana de Jefes de Estado y de Gobierno, donde se reconocía expresamente la importancia de reforzar el papel de la cultura; o la Declaración de Hangzhou que intentaba situar a la cultura en el centro de las políticas de desarrollo sostenible y donde se comprometen a: “...tomar plenamente en cuenta el papel de la cultura como sistema de valores y como recurso y marco para construir un desarrollo auténticamente sostenible, la necesidad de aprender de las experiencias de las generaciones pasadas y el reconocimiento de la cultura como parte del patrimonio común y local y como fuente de creatividad y de renovación”. Todos estos compromisos parecen ser una burla por los que toman las decisiones políticas en algunos de nuestros países.

Este año 2015, reunidos en Bilbao los días 18 al 20 de marzo, representantes de ciudades y gobiernos locales de todo el mundo, convocados por la Organización Mundial de Ciudades y Gobiernos Locales Unidos (CGLU) en su Cumbre de Cultura, adoptaron un documento titulado: Agenda 21 de la cultura que aspira, no solo a reconocer el potencial de la cultura, sino también a revalorar la absoluta necesidad de la cultura para el desarrollo sostenible.

La Agenda 21 de la cultura tiene su primer antecedente en el año 2014 cuando se crea el primer documento, con vocación mundial, que apostaba por establecer las bases de un compromiso de las ciudades y los gobiernos locales para el desarrollo cultural. Fue aprobada por ciudades y gobiernos locales de todo el mundo comprometidos con los derechos humanos, la diversidad cultural, la sostenibilidad, la democracia participativa y la generación de condiciones para la paz. Su aprobación tuvo lugar el 8 de mayo de 2004 en Barcelona, por el IV Foro de Autoridades Locales para la Inclusión Social de Porto Alegre, en el marco del Primer Foro Universal de las Culturas.

El nuevo documento complementa a la Agenda 21 de la cultura, aprobada hace 10 años. Se puntualiza que la Cultura es el Cuarto Pilar para el desarrollo sostenible.

En el 2015, en la VII Cumbre de Las Américas que se celebró en nuestro país el 10 y 11 de abril, el Movimiento Ciudadano por la Identidad Panameña, en un Mensaje a la Nación Panameña remarcó 
Invest. pens. crit.

Vol. 3, No. 3, septiembre-diciembre 2015

pp. $80-90$

esta nueva noción de la Cultura como Cuarto Pilar del Desarrollo y recordó las orientaciones recientes donde "la cultura sea incluida en este modelo de desarrollo, aseverando que la cultura al fin y al cabo moldea lo que entendemos por desarrollo y determina la forma de actuar de las personas en el mundo". En la mesas de la VII Cumbre de Las Américas la cultura no estaba incluida como tema y la Mesa de Educación fue retitulada como Mesa de Educación y Cultura, gracias a la intervención de personas preocupadas por el tema.

\section{Nuestro problema, nuestra crítica y nuestra propuesta}

Los sucesivos gobiernos panameños a partir de la Post Invasión (para situarnos en un periodo de tiempo), han elaborado planes y programas de desarrollo a través de comisiones que estudian el comportamiento del desarrollo, la economía y lo social para diseñar y elaborar los proyectos y acciones que desembocan en un plan estratégico para cambiar el país o para edificar un proyecto de nación. Esto sucede siempre en todos los primeros meses de un gobierno, y, sin embargo, es curioso observar, sobre todo si tenemos en cuenta los referentes históricos que acabamos de citar, que la cuestión cultural siempre queda por fuera.

Desde mi derecho como ciudadano y persona del sector cultura quiero elevar una crítica constructiva, y a la vez añadir una propuesta, al Plan Estratégico de Gobierno (de ahora en adelante: PEG) del Presidente Juan Carlos Varela.

El PEG para el próximo quinquenio tiene muchas posibilidades de ser un buen Plan, pero está cojo y esa cojera es la ausencia de la cultura como un componente del desarrollo. Hubiese sido muy positivo para el gobierno del Ingeniero Juan Carlos Varela que dentro de las acciones concretas para elaborar el PEG se hubiese incluido el desarrollo cultural como uno de los pilares del desarrollo sostenible. Hubiese sido saludable que la palabra Cultura estuviese en cada uno de los ejes temáticos. De cualquier forma, y como dicen que nada está escrito en piedra y que nunca es tarde para rectificar, dejo estas observaciones usando el plural de modestia porque creo que el sector cultura estará de acuerdo conmigo.

\section{Mirada de pájaro en diez vueltas.}

Uno. El PEG para el próximo quinquenio se basa en cuatro ejes fundamentales: una Estrategia Social, una Estrategia Económica, un Plan Quinquenal de Inversiones y una Programación Financiera. Sin embargo, no se plantea una Estrategia desde el desarrollo cultural. Una estrategia Cultural lo fortalecería y lo articularía con todos los temas. Una estrategia desde la cultura implicaría tener en cuenta un crecimiento no sólo vertical, sino horizontal y diversificado que comprendería la equidad en todas sus formas.

Dos. El PEG tiene como premisa la equidad social, lograr elevar el nivel de vida de todos los panameños, impulsando un crecimiento económico sostenible para lograr que el país siga avanzando hacia 
un "Panamá que crece, crezca para todos". No obstante, nociones como equidad y crecimiento sostenible, son impensables en un país sin desarrollo cultural. También en la cultura existen desigualdades que frenan el crecimiento económico y lo empobrecen o, lo convierten en un crecimiento vertical que es peor.

Tres. El PEG contempla como sectores motores de la economía panameña, la logística y el transporte, la agricultura y el turismo, incluso la minería, pero la cultura como dispositivo para el desempeño económico del país desde sus distintos motores que generan riqueza y empleo, por ejemplo, las industrias culturales, el consumo cultural, la circulación de bienes culturales y la creación artística, no se mencionan en el documento. La cultura es motor del desarrollo sostenible.

Cuatro. Sectores específicos, como el sector energético, recibirán un importante impulso por parte del gobierno, pero el sector cultura sigue siendo la cenicienta del país y no se le considera relevante para el desarrollo y el presupuesto para la cultura sigue siendo el más pobre que ni siquiera llega al 0.20\%. Se necesita, al menos, un compromiso al 1\% del gasto nacional dirigido a la cultura. Es menester tener la cultura como una prioridad en la agenda del Estado y, sobre todo, tener una visión de ella como un pilar del desarrollo. Hoy día, no lo es.

Cinco. Desde el sistema de derechos humanos y sociales básicos se ha pensado en los tratados, convenios y acuerdos internacionales en términos de, citamos: derechos universales; derechos de la juventud y los menores; derechos de la mujer, y relativos a la nacionalidad, las migraciones, los refugiados y apátridas; así como aquellos correspondientes a derechos de: la educación, la cultura y el deporte; la salud y la seguridad social, y en materias de trabajo y derecho laboral, entre otros. Sin embargo, aunque se menciona la palabra cultura, no existe claridad que garantice los medios y condiciones necesarias para optimizar el desarrollo de la creación artística y que la población tenga derecho a la cultura. Esto es la falta de equipamientos y programas culturales de diversos tipos, entre muchas otras necesidades en el sector.

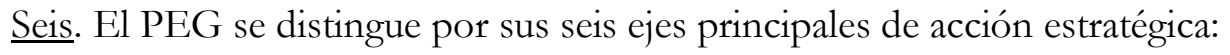

- EJE 1: Bienestar y Desarrollo Humano; "vida buena para todos".

- EJE 2: Fortalecimiento de la democracia y del Estado de Derecho ('Renovar la República').

- EJE 3: Desarrollo económico sostenible ('Crecimiento con equidad').

- EJE 4: Seguridad ciudadana ('barrios seguros con más oportunidades y mano firme').

- EJE 5: Política exterior al servicio del desarrollo ('Panamá capital de las Américas').

- EJE 6: Respeto, defensa y protección del medio ambiente ('Ambiente sano para todos’).

Solamente en el primer eje se menciona a la Cultura: atención a grupos vulnerables, sanidad básica, salud pública accesible y eficiente, vivienda digna y adecuada, educación bilingüe de calidad, transporte público, y participación ciudadana en actividades científicas, culturales y deportivas. Creemos que la cultura es un eje transversal que puede re-posicionar y re-significar todos los otros ejes, sin embargo 
Invest. pens. crit.

Vol. 3, No. 3, septiembre-diciembre 2015

pp. $80-90$

no se percibe como una herramienta para la articulación. Por ejemplo: cómo la cultura puede ayudar a mermar la violencia y la delincuencia; cómo la cultura puede ayudar a hacer docencia en términos de salud; cómo la cultura puede construir ciudadanía que cree conciencia hacia muchos problemas como el medio ambiente, por mencionar algunos.

Siete. El PEG menciona los Acuerdos de la Concertación Nacional para el Desarrollo (octubre de 2007), donde se hablaba de un país desarrollado y equitativo. Pese a que esos acuerdos apuntaban a: $1^{\circ}$. Crecer más y mejor; $2^{\circ}$. Crecer con más equidad y menos pobreza; $3^{\circ}$. Articular el desarrollo de 'un solo país', equilibrad territorialmente; y $4^{\circ}$. Alcanzar una sociedad más democrática y más ética. Es evidente que ese país equitativo es una utopía y, para que exista una posibilidad real, es vital resolver las necesidades básicas de la población y tener a la cultura en cuenta como una herramienta para mejorar la calidad de vida de la población. Es necesario que al mismo tiempo que se creen las condiciones económicas y políticas, se creen las condiciones culturales para mejorar la calidad de vida de las personas.

Ocho. El PEG nos habla de UN SOLO PAÍS, integrado y cohesionado, con armonía social y sostenibilidad ambiental, generador de buenas condiciones de vida y de oportunidades de desarrollo humano, dinámicamente posicionado en el escenario regional y mundial. Esta visión de país se basa, a su vez, en una visión de crecimiento sostenido de la economía que propone: 1. Crecer más y mejor, 2. Buena vida para todos, 3. Un país sostenible, multi-étnico, territorial y culturalmente integrado, y 4. Un solo país renovado con una propuesta de Gobernanza democrática, inclusiva y eficiente. Pero, ¿cómo lograremos estos objetivos en un país donde el Estado no tiene conciencia de la importancia del impacto económico y social de la cultura?; ¿cómo tener un proyecto de país sin tener en cuenta que la cultura es una inversión a largo plazo?; ¿cómo construir ese país soñado sin hacer conexiones cívicas desde las posibilidades que brinda el desarrollo cultural?

Nueve. El PEG apuesta por el turismo y le dedica un espacio relevante en el documento, y, pese a que se habla en este apartado de impulsar un Plan Maestro Nacional de Cultura, no entendemos por qué está insertado en Turismo cuando tenemos el INAC que como institución solo necesita tener poder para legislar en torno a una política cultural y un presupuesto digno para poder trabajar.

También se menciona un Consejo Consultivo de Cultura pero es contradictorio al mismo tiempo cuando la cultura, que es el principal atractivo de un país, carece de la misma preocupación y recursos. Se menciona, por otra parte, al museo de la Biodiversidad, pero no se habla de fortalecer nuestros museos que guardan la memoria del país, principalmente el Museo Antropológico Reina Torres de Arauz. El subtítulo: Valoración y rehabilitación del Patrimonio Cultural, está vacío y no tiene propuestas. Los turistas llegan a un país sin memoria con una débil aproximación que se limita al Casco Antiguo o el Centro Turístico de Panamá Viejo o simplemente a distraerse con las rutas turísticas. El PEG no habla de potenciar los festivales, fiestas y ferias. 
Diez. Consideramos que se incluya como estrategia un Plan Nacional de Desarrollo Cultural y que se aspire a un Ministerio de Cultura que posibilite destinar mayores recursos al desarrollo cultural. Apelamos a que la cultura sea, de una vez por todas, considerada una prioridad para el país, uno de los pilares del desarrollo sostenible, porque con la cultura se puede construir UN SOLO PAÍS basado en el derecho a la creación y donde esos derechos culturales se respeten y se creen las condiciones óptimas para que la cultura (la ciencia, la técnica, las humanidades, el arte) sea una fuente de riqueza y desarrollo, y deje de considerarse una fuente de mero entretenimiento y diversión.

\section{Propuestas y Conclusiones}

Proponemos al gobierno del señor Presidente Juan Carlos Varela:

Uno. Tener como referente el documento: La cultura es el cuarto pilar del desarrollo sostenible Aquí y Cultura 21: Acciones Aquí. Documentos que hemos citado en este trabajo y están en la bibliografía.

Dos. Repensar la cultura desde los siguientes soportes conceptuales para que de esta forma se puedan construir líneas de acción puntuales desde la cultura:

- Soporte biológico: La cultura como un sistema multidimensional e integrador de la ecología humana.

- Soporte científico: La cultura como elemento para la creación de conocimiento e innovación.

- Soporte filosófico: La cultura como generadora de ideas y reflexión.

- Soporte pedagógico: La cultura como fundamento para la formación de ciudadanos íntegros.

- Soporte sociocultural: La cultura como herramienta indispensable para el cambio social y la construcción ciudadana.

- Soporte socioeconómico: La cultura como dispositivo para la circulación de bienes culturales que favorecen el desarrollo económico.

- Soporte político: La cultura como componente para la construcción de un proyecto de Nación.

Tres: Para poder problematizar el tema de la cultura hay que entenderlo. Existen documentos nacionales valiosos que han nacido de importantes conclaves locales y que sirven de referencia para entender el problema de la cultura en Panamá. Sólo hay que leer.

En 1974, con ayuda de UNESCO, se redactó: Política Cultural de la República de Panamá; en 1983, con la administración del Doctor Diógenes Cedeño Cenci en el INAC, se realiza el Primer Encuentro Nacional de Política Cultural, quedó una memoria del evento. En abril de 1999, bajo la dirección del doctor Jorge Delgado Castellanos, se celebra el Segundo Encuentro de Política Cultural que deja un documento con el título: Lineamientos para una política Cultural del Estado Panameño. Más tarde, el Instituto Nacional de Cultura a cargo del memorable Anel Omar Rodríguez Barrera, creó una comisión que revisó la Política Cultural vigente que abrió el camino para la creación de la Ley General de Cultura que asesinaron en la cuna. 
Invest. pens. crit.

Vol. 3, No. 3, septiembre-diciembre 2015

pp. $80-90$

La historia no perdona ni deja cabos sueltos. El gobierno del Presidente Juan Carlos Varela tiene la oportunidad de hacer historia y coronar la cultura dándole la preocupación que se merece.

Cuatro. El PEG habla de un Plan Nacional de Cultura. Pero ya existe un PNC y sólo hace falta que el INAC tenga potestad legal para crear políticas culturales y ejecutarlas. Un Plan Nacional de Cultura sin Ministerio o Autoridad de Cultura es letra muerta. No entendemos por qué el PEG señala que Turismo liderará este Plan. Se menciona la idea de crear la Secretaria Nacional de Cultura, pero no queda claro dónde estará insertada esta secretaría; y, de crearse esta entidad, ¿cómo queda el INAC y qué sitio ocupará la institución?

Cinco. Destinar al Instituto Nacional de Cultura un presupuesto equiparado con el destinado a los ministerios, porque el INAC, como regente de la cultura del país, no puede operar con el endémico presupuesto que tiene actualmente. Como ya mencionamos se necesita mínimo el 1\% del gasto nacional para la cultura. En s momentos no llega ni al 0.20\%. También se necesitan incentivos fiscales para que el sector privado invierta en la cultura. De esta forma el sector cultura tendría más recursos.

\section{Posdata}

Quisiera terminar haciendo eco de las palabras de la presidenta de la hermana República de Argentina, la señora Cristina Fernández de Kiechner, que en la Cumbre de Las Américas celebrada en abril pasado, cerró su intervención diciendo que debemos abordar nuestros problemas con sinceridad, sin miedo a las ideas y con un conocimiento de la historia. He querido ser sincero en este breve texto, citando algo de historia y haciendo uso del conocimiento y de las ideas para aportar un grano de arena a la construcción con equidad e igualdad del país que queremos.

La historia de los fracasos de las estrategias económicas de los sucesivos gobiernos nacionales se ha debido por excluir a la cultura de los procesos de desarrollo. De hecho, ha sido la historia de los fracasos en América Latina. No lo dice este servidor, lo dicen los expertos como Germán Rey: "La cultura no podía estar ajena a la tematización del desarrollo. Primero como un factor inevitable aunque realmente poco resaltado por los énfasis economicistas y después como una dimensión central que parecía abrir las compuertas de aquellos modelos del desarrollo que fracasaron por extrapolaciones sin cultura, por aplicaciones sin historia".

La cultura ya no es algo accesorio de mero entretenimiento, es un hecho transversal que está implícito en todas las esferas del conocimiento y que es vital, no sólo para un verdadero desarrollo sostenible, sino también para construir una sociedad con normas de convivencia que nos ayuden a resolver nuestros problemas. No lo dice este humilde servidor, lo dicen especialistas como Néstor García Canclini: "Demasiados conflictos actuales se explican, en parte, por haber olvidado que el desarrollo económico no se reduce a crecimiento, baja inflación y equilibrio en la balanza comercial, y que el desarrollo social incluye esa dimensión propia de la cultura que es encontrarle sentido a lo que hacemos". 
En el marco de la ciudadanía social, desde las tensiones políticas y los conflictos sociales; desde las identidades, los géneros, el derecho, la ética y los valores; desde los imaginarios de identidad, la religiosidad, los ritos, la fiesta; desde las sexualidades y los tabúes; desde la tribu, el guetto, el club social; desde los movimientos y las sensibilidades posmodernas; desde las redes sociales y comunicacionales, la información, la ciencia y la tecnología; desde lo público y lo privado; desde los organismos culturales de base, las instituciones, las asociaciones, las ONGs; desde la educación, la salud, las ciencias sociales, el deporte; desde todo el universo de complejidades que incluye a la criatura humana, la cultura está implícita y es el lugar ubicuo para tejer espacios de convivencia, para dignificar lo que es humano, para dialogar entre todos y buscar respuestas. Si se quiere en serio un Solo País, se debe repensar lo que significa la cultura y tenerla como una prioridad en la estrategia de los que nos gobiernan.

El título de este texto lo rotulé: La Cultura en la cumbre. Sé que es paradójico, incluso, sarcástico, pero significa o quiere significar algo: quizá en la pasada Cumbre de Las Américas la palabra cultura no fue tan importante como otros temas que sí han sido tomados en cuenta; quizá la Cultura no estuvo en la "cumbre" y solo fue un adorno para entretener a los mandatarios; no importa. Lo importante es que nuestro país, su gobierno, los políticos, los líderes, el Presidente y su equipo, pueden poner a la Cultura en la cumbre y tal vez, solo tal vez, podamos hablar de un solo país para todos.

\section{Agradecimientos}

Agradezco profundamente al doctor Javier Stanziola por sus importantes observaciones a este texto y a Alexandra Schjelderup por facilitarme algunos documentos que me ayudaron en la redacción.

\section{Referencias}

Bunge, M. (1997). Ciencia, técnica y desarrollo. Buenos Aires, Argentina: Ed. Sudamericana.

Bunge, M. (1997). Vistasy entrevistas. Propuestas concretas sobre los problemas de nuestro tiempo. Buenos Aires, Argentina: Ed. Sudamericana.

Carta Cultural Iberoamericana, XVI Cumbre Iberoamericana de Jefes de Estado y de Gobierno, Montevideo, noviembre 2006.

Comisión Mundial de Cultura y Desarrollo. (1997). Nuestra diversidad creativa: Informe de la Comisión Mundial de Cultura y Desarrollo. México: UNESCO.

Convenio Andrés Bello (2001). Memorias del Seminario internacional sobre economía y cultura: La tercera cara de la moneda (16-18 de mayo de 2000). Bogotá, Colombia: autor

Cultura 21: Acciones, Cumbre de Cultura de la Organización Mundial de Ciudades y Gobiernos Locales Unidos (CGLU), Bilbao, marzo 2015. 
Invest. pens. crit.

Vol. 3, No. 3, septiembre-diciembre 2015

pp. $80-90$

Declaración de Hangzhou Situar la cultura en el centro de las políticas de desarrollo sostenible. Aprobada en Hangzhou (República Popular de China), el 17 de mayo de 2013.

Declaración de Margarita. Para una ética de la integración cultural. Isla de Margarita, Venezuela 20 y 21 de octubre de 1997.

García, N. (febrero de 2005). Todos tienen cultura: ¿quiénes pueden desarrollarla? Conferencia para el Seminario sobre Cultura y Desarrollo, en el Banco Interamericano de Desarrollo, Washington, EEUU.

García, N., Ottome, E. y Batista, M. (1997). La economía de la cultura Iberoamericana. Madrid, España: OEI y Fundación CEDEAL.

Gobierno de la República de Panamá. (2014). Plan Estratégico de Gobierno 2015-2019, “Un solo país”. Panamá: autor.

La cultura es el cuarto pilar del desarrollo sostenible. Aprobado el día 17 de noviembre de 2010, en el marco de la Cumbre Mundial de Líderes Locales y Regionales - 3er Congreso Mundial de CGLU, celebrado en la Ciudad de México. Leer documento Aquí

Ocampo, J. A. (2005). Más allá del Consenso de Washington: Una agenda de desarrollo para América Latina. Comisión Económica para América Latina (CEPAL): Serie estudios y perspectivas, 26. Disponible en http://repositorio.cepal.org/

Parenti, M. (2009). La batalla de la cultura. La Habana, Cuba: Editorial de Ciencias Sociales.

Rey, G. (2002). Cultura y desarrollo humano: Unas relaciones que se trasladan. Pensar Iberoamérica: Revista de cultura. Disponible en http://www.oei.es/pensariberoamerica 